(2) Open Access Full Text Article

REVIEW

\title{
Integrating lifestyle-focused approaches into psoriasis care: improving patient outcomes?
}

This article was published in the following Dove Press journal:

Psoriasis: Targets and Therapy

19 January 2016

Number of times this article has been viewed

\author{
Angelo Landriscina' \\ Adam J Friedman ${ }^{2,3}$ \\ 'Department of Medicine (Division \\ of Dermatology), Montefiore Medical \\ Center, Bronx, NY, USA; ${ }^{2}$ Department \\ of Physiology and Biophysics, Albert \\ Einstein College of Medicine, \\ Bronx, NY, USA; ${ }^{3}$ Department of \\ Dermatology, George Washington \\ School of Medicine and Health \\ Sciences, Washington, DC, USA
}

\begin{abstract}
Psoriasis is one of the most well described cutaneous disorders, with a large body of literature devoted to describing its pathogenesis and treatment. In recent years, attention has turned toward the mechanisms by which lifestyle can impact psoriatic disease, and how lifestyle interventions may help to alleviate cutaneous, rheumatological, and comorbid disease in the setting of psoriasis. The following review explores our current understanding of the interaction between lifestyle factors and psoriasis and describes outcomes of interventions meant to target these factors.
\end{abstract}

Keywords: psoriasis, lifestyle, tobacco, alcohol, obesity, depression

\section{Introduction}

Psoriasis is perhaps the most studied of dermatologic disorders, with an expansive body of literature devoted to describing its pathogenesis and treatment. It is largely understood to be an inflammatory disorder with both genetic and environmental factors contributing to its development. As such, treatment strategies for psoriasis tend to focus on anti-inflammatory and immunomodulating therapies ranging from topical corticosteroids to systemic immunosuppressive agents including biologics. Over the last decade, interest has grown in the way that lifestyle impacts disease progression in patients with psoriasis, and how lifestyle modification-based strategies can help to create a holistic approach to therapy for optimal outcomes in the face of cutaneous, rheumatologic, and comorbid manifestations. The following review outlines our current understanding of how lifestyle factors impact psoriasis and its many manifestations, and describes outcomes of interventions targeted at optimizing these factors.

\section{Lifestyle factors and interventions Smoking and smoking cessation}

Tobacco smoking represents one of the greatest public health risks, due to its widespread use (estimated at $22 \%$ of the population) ${ }^{1}$ and role as a risk factor for the development of cerebrovascular disease, coronary artery disease, myocardial infarction, COPD, and a host of malignancies. ${ }^{2,3}$ Evidence has also shown that tobacco smoking is associated not only with the development of psoriasis, with a larger effect seen in women, but also worsening severity of cutaneous disease in a dose-dependent fashion and altered response to treatment. ${ }^{4-8}$ These effects are well described in a systematic review and meta-analysis by Armstrong et al, which found an increased risk of developing psoriasis with both greater duration of smoking and quantity of cigarettes
Correspondence: Adam J Friedman Department of Dermatology, George Washington School of Medicine and Health Sciences, 2150 Pennsylvania Avenue, 2b, Washington DC 20037, USA Tel +l 202-677-6I57

Email ajfriedman@mfa.gwu.edu
Psoriasis: Targets and Therapy 2016:6 I-5

(c) (1) (2) ( 2016 Landrisina and Friedman. This work is published and licensed by Dove Medical Press limited. The full terms of this license are avalable at https:/www.

Dovepress

http://dx.doi.org/10.2147/PTT.S81957
BY dovepress.com/terms.php and incorporate the Creative Commons Attribution - Non Commercial (unported, v3.0) License (http:///creativecommons.org/licenses/lby-nc/3.0/). B accessing the work you hereby accept the Terms. Non-commercial uses of the work are permitted without any further permission from Dove Medical Press Limited, provided the work is properly attributed. For permission for commercial use of this work, please see paragraphs 4.2 and 5 of our Terms (https://www.dovepress.com/terms.php). 
smoked per day in both current and former smokers, as well as a higher likelihood of current or former tobacco use in psoriasis patients versus controls. ${ }^{7}$

It is thought that tobacco use impacts psoriatic disease much in the same way that it exerts its toxic effects on the pulmonary and cardiovascular systems. First, cigarette smoking is a source of oxidative stress, introducing free radicals into the body, and decreasing antioxidant resources/systems. ${ }^{9}$ Given lesional psoriatic skin was found to be overwhelmed with an overabundance of reactive oxygen species and therefore depletion of antioxidants, smoking would only increase this imbalance. ${ }^{10}$ Substances found in tobacco have also been found to alter the expression of a host of inflammatory signals, including many known to be dysregulated in psoriatic disease. ${ }^{11-16}$

It has also been known for some time that patients with psoriasis often exhibit a greater risk for medical comorbidities including hypertension, diabetes, obesity, dyslipidemia, and the metabolic syndrome. ${ }^{17-21}$ These together with the known effects of smoking may create a perfect storm of risk factors for a cardiovascular or cerebrovascular event. Taking all of the above information into account, one can posit that smoking cessation would be a positive step toward alleviating cutaneous disease and diminishing comorbid risk factors for psoriasis patients. However, there is a glaring gap in the literature when it comes to smoking cessation initiatives and outcomes in patients with psoriasis, leaving many questions unanswered. While we know that smoking can affect psoriatic disease in a dose-dependent fashion, we have yet to discover whether or not smoking cessation improves cutaneous disease, or response to treatment. While smoking cessation has been shown to alter the course of cardiovascular and cerebrovascular disease, it has yet to be demonstrated whether or not the effect size of this intervention is altered in patients with psoriasis. Lastly, patients with psoriasis undergo additional physical and psychological stress, which may explain the higher rate of tobacco use in psoriasis patients over the general population. It is not yet known whether specific smoking cessation interventions are less effective for patients with psoriasis. In the absence of this data, providers should screen for tobacco use as part of a comprehensive approach to care, and offer smoking cessation interventions to motivated patients with psoriatic disease.

\section{Obesity and weight loss interventions}

Obesity has reached epidemic proportions in the global population, with obesity rates doubling since $1980 .^{22}$ While many factors contribute to obesity, certain disease states, psoriasis among them, have been found to be independent risk factors for the development of obesity. ${ }^{23}$ Several metaanalyses have found that patients with psoriasis have $>50 \%$ increased odds of obesity, and that this association is greater with increased severity of cutaneous disease. ${ }^{18,24}$ Furthermore, more profound cutaneous disease is associated with a greater degree of obesity. ${ }^{24}$ These associations are reflected in epidemiologic data demonstrating that psoriasis patients have a higher prevalence of obesity and a greater average body mass index when compared to the general population. ${ }^{25}$

Obesity is similar to psoriasis in that it is largely understood as a pro-inflammatory state. Adipose tissue is immunologically active, releasing soluble signals in the form of adipokines in response to pro-inflammatory signals from macrophages. ${ }^{18}$ The result of this process is augmentation of circulating pro-inflammatory cytokines, including IL-6 and TNF- $\alpha$, which are dysregulated and used as treatment targets in psoriasis and psoriatic arthritis. ${ }^{26}$ While these correlations provide a basis for understanding the association between obesity and psoriatic disease, a mechanism of progression from one condition to the other has not been identified. Given the known links that both psoriasis and obesity have to cardiovascular and cerebrovascular disease, one pro-inflammatory etiology may link these conditions, their comorbidities, and their ultimate outcomes.

While some studies have found that obesity does not impact the course of treatment in patients with psoriasis, several prospective studies have shown decreased severity of disease and comorbid conditions when patients are randomized to low calorie diets with or without prescribed exercise programs. ${ }^{27-29}$ There have also been several reported cases documenting remission of cutaneous disease following bariatric surgery. ${ }^{30,31}$ These reports considered, there is still a dearth of information regarding targeted weight loss interventions for patients with psoriasis. Larger, more detailed trials documenting progression of disease, response to treatment, and overall mortality in psoriasis patients who are prescribed weight loss regimens will be key to fully elucidating the link between obesity and psoriatic disease. Nevertheless, providers should screen psoriasis patients for obesity, and recommend appropriate interventions to control weight including diet, exercise, and consultation with a dietician.

\section{Alcohol use and alcohol abstinence measures}

The association between alcohol abuse and psoriatic disease has been known for decades, though the mechanism of this association is still unknown. ${ }^{32}$ While low level alcohol 
consumption may be protective against some disease states, the correlation between psoriasis and alcohol use is troubling. Studies have suggested that the amount of alcohol consumed by patients on a regular basis correlates with severity of cutaneous disease. ${ }^{33} \mathrm{~A}$ recent study by Zou et al found that alcohol intake as measured by serum measures or phosphatidylethanol correlated with increasing Psoriasis Area and Severity Index scores. ${ }^{33}$ Furthermore, it has been shown that psoriasis puts patients at risk for non-alcoholic fatty liver disease. ${ }^{34}$ This combined with the hepatic damage caused by alcohol and the widespread use of hepatotoxic drugs such as methotrexate for the treatment of psoriasis create a concerning constellation of risk factors for liver disease.

The link between psoriatic disease and alcohol intake is again, formed by immunostimulation and induction of inflammation. Alcohol use has been found to stimulate the $\mathrm{T}_{\mathrm{H}^{-}}{ }^{-1}$ immune response, which is already dysregulated in psoriasis, and also results in alterations to the expression of a host of cytokines that include IL-6 and TNF- $\alpha .{ }^{35-38}$ These mechanisms may link alcohol consumption, psoriasis, and liver disease.

Alcohol use is yet another area in which specific interventions for psoriasis patients have not been studied. However, it is advisable that providers make an effort to screen patients with psoriatic disease for alcohol abuse and track hepatic function, especially in the face of treatment with drugs like methotrexate, which when combined with alcohol will be hepatotoxic; or even TNF- $\alpha$-blocking biologics.

\section{Mood symptoms, depression, and mood-based interventions}

Cutaneous disease has the potential to affect all levels of a patient's functioning. Pain, pruritus, and sleep disturbances together with the psychosocial effects of having a visible disorder and additional disease-related stressors (missed work, hospitalization) can result in a significant psychological impact on the patient. Observational studies have described in detail the ways in which psoriasis and depression are linked, showing that risk of depression in psoriasis patients is greater than that of the population (1.5 times more likely by some estimates), that the risk of new onset depression is greater in those with more intense disease, and those with psoriatic arthritis and other comorbidities, and that the risk of depression and suicidal ideation in inpatients treated for psoriasis is greater than that of sufferers of other cutaneous disorders. ${ }^{39-43}$ Furthermore, commonly used therapies for psoriasis like etanercept may also pose a depression risk. ${ }^{44}$

There are available strategies for treatment of psoriasisassociated mood symptoms and depression, with new options on the horizon. Firstly, providers should screen psoriasis patients for mood symptoms using a simple instrument such as the Personal Health Questionaire-2. If clinical depression is suspected, providers can consider referring patients for psychiatric evaluation and treatment. Depressive symptoms may also be alleviated by treatment of cutaneous disease, as has been shown with the use of several biologics, including etanercept, in spite of the findings mentioned. ${ }^{45}$ Mindfulness-based cognitive therapy has also shown promise in a recent pilot study that showed patients receiving therapy reported decreased Psoriasis Area and Severity Index scores and overall higher quality of life than those who underwent standard psoriasis treatment. ${ }^{46}$ While these results are promising, a randomized control trial is needed to fully elucidate the effect of this kind of therapy. Other behavioral approaches should also be investigated as a possible adjunctive therapy to prevent or treat psoriasis-associated mood symptoms and depression.

\section{Conclusion}

Psoriasis is a disease process with both cutaneous and rheumatologic manifestations that affects all aspects of patients' lives. While psoriatic disease is likely caused by a genetic predisposition, other intrinsic and environmental factors, including those linked to lifestyle play a role in the development and progression of disease including tobacco and alcohol use and obesity. Other conditions, such as depression and other mood systems, exist concomitantly with psoriatic disease, and take an additional toll on the lives of patients. Given the nature of these factors, lifestyle-based interventions are likely to improve morbidity and mortality for patients, though there are little data examining their specific use in patients with psoriasis. Furthermore, physicians are ill-equipped and scarcely motivated to provide these types of interventions. ${ }^{47}$ Additional high quality data are likely to both elucidate the utility of such interventions and improve physician confidence in providing them.

\section{Disclosure}

The authors have no conflict of interest to disclose.

\section{References}

1. Giovino GA, Mirza SA, Samet JM, et al. Tobacco use in 3 billion individuals from 16 countries: an analysis of nationally representative cross-sectional household surveys. Lancet. 2012;380(9842):668-679.

2. Lakier JB. Smoking and cardiovascular disease. Am J Med. 1992; 93(1A):8S-12S.

3. Fielding JE. Smoking: health effects and control (1). NEngl J Med. 1985; 313(8):491-498.

4. Poikolainen K, Reunala T, Karvonen J. Smoking, alcohol and life events related to psoriasis among women. Br J Dermatol. 1994;130(4): $473-477$. 
5. Naldi L, Parazzini F, Brevi A, et al. Family history, smoking habits, alcohol consumption and risk of psoriasis. Br J Dermatol. 1992;127(3): 212-217.

6. Fortes C, Mastroeni S, Leffondré K, et al. Relationship between smoking and the clinical severity of psoriasis. Arch Dermatol. 2005;141(12): 1580-1584.

7. Armstrong AW, Harskamp CT, Dhillon JS, Armstrong EJ. Psoriasis and smoking: a systematic review and meta-analysis. Br J Dermatol. 2014;170(2):304-314.

8. Kinahan CE, Mazloom S, Fernandez AP. Impact of smoking on response to systemic treatment in patients with psoriasis: a retrospective casecontrol study. Br J Dermatol. 2015;172(2):428-436.

9. Yanbaeva DG, Dentener MA, Creutzberg EC, Wesseling G, Wouters EF. Systemic effects of smoking. Chest. 2007;131(5):1557-1566.

10. Emre S, Metin A, Demirseren DD, Kilic S, Isikoglu S, Erel O. The relationship between oxidative stress, smoking and the clinical severity of psoriasis. J Eur Acad Dermatol Venereol. 2013;27(3):e370-e375.

11. Armstrong AW, Armstrong EJ, Fuller EN, Sockolov ME, Voyles SV. Smoking and pathogenesis of psoriasis: a review of oxidative, inflammatory and genetic mechanisms. Br J Dermatol. 2011;165(6):1162-1168.

12. Byron KA, Varigos GA, Wootton AM. IL-4 production is increased in cigarette smokers. Clin Exp Immunol. 1994;95(2):333-336.

13. Flisiak I, Chodynicka B, Porebski P, Flisiak R. Association between psoriasis severity and transforming growth factor beta (1) and beta (2) in plasma and scales from psoriatic lesions. Cytokine. 2002;19(3): 121-125.

14. Okubo Y, Koga M. Peripheral blood monocytes in psoriatic patients overproduce cytokines. J Dermatol Sci. 1998;17(3):223-232.

15. Ryder MI, Saghizadeh M, Ding Y, Nguyen N, Soskolne A. Effects of tobacco smoke on the secretion of interleukin-1beta, tumor necrosis factor-alpha, and transforming growth factor-beta from peripheral blood mononuclear cells. Oral Microbiol Immunol. 2002;17(6):331-336.

16. Sonnex TS, Carrington P, Norris P, Greaves MW. Polymorphonuclear leukocyte random migration and chemotaxis in psoriatic and healthy adult smokers and non-smokers. Br J Dermatol. 1988;119(5):653-659.

17. Armstrong AW, Harskamp CT, Armstrong EJ. Psoriasis and metabolic syndrome: a systematic review and meta-analysis of observational studies. J Am Acad Dermatol. 2013;68(4):654-662.

18. Armstrong AW, Harskamp CT, Armstrong EJ. The association between psoriasis and obesity: a systematic review and meta-analysis of observational studies. Nutr Diabetes. 2012;2:e54.

19. Armstrong AW, Harskamp CT, Armstrong EJ. Psoriasis and the risk of diabetes mellitus: a systematic review and meta-analysis. JAMA Dermatol. 2013;149(1):84-91.

20. Armstrong AW, Harskamp CT, Armstrong EJ. The association between psoriasis and hypertension: a systematic review and meta-analysis of observational studies. J Hypertens. 2013;31(3):433-442; discussion 442-433.

21. Armstrong AW, Lin SW, Chambers CJ, Sockolov ME, Chin DL. Psoriasis and hypertension severity: results from a case-control study. PloS One. 2011;6(3):e18227.

22. World Health Organization [homepage on the Internet]. Obesity and overweight: fact sheet no 311. WHO; 2015. Available from: http://www. who.int/mediacentre/factsheets/fs311/en/. Accessed November 24, 2015.

23. Kaye JA, Li L, Jick SS. Incidence of risk factors for myocardial infarction and other vascular diseases in patients with psoriasis. Br J Dermatol. 2008;159(4):895-902.

24. Fleming P, Kraft J, Gulliver WP, Lynde C. The Relationship of Obesity With the Severity of Psoriasis: A Systematic Review. J Cutan Med Surg. 2015;19(5):450-456.

25. Jacobi A, Langenbruch A, Purwins S, Augustin M, Radtke MA. Prevalence of Obesity in Patients with Psoriasis: Results of the National Study PsoHealth3. Dermatology. 2015;231(3):231-238.

26. Sterry W, Strober BE, Menter A; International Psoriasis Council. Obesity in psoriasis: the metabolic, clinical and therapeutic implications. Report of an interdisciplinary conference and review. Br J Dermatol. 2007;157(4):649-655.
27. Herron MD, Hinckley M, Hoffman MS, et al. Impact of obesity and smoking on psoriasis presentation and management. Arch Dermatol. 2005;141(12):1527-1534.

28. Debbaneh M, Millsop JW, Bhatia BK, Koo J, Liao W. Diet and psoriasis, part I: Impact of weight loss interventions. J Am Acad Dermatol. 2014;71(1):133-140.

29. Naldi L, Conti A, Cazzaniga S, et al. Diet and physical exercise in psoriasis: a randomized controlled trial. Br J Dermatol. 2014;170(3): 634-642.

30. de Menezes Ettinger J, Azaro E, de Souza C, et al. Remission of Psoriasis after Open Gastric Bypass. Obes Surg. 2006;16(1):94-97.

31. Higa-Sansone G, Szomstein S, Soto F, Brasecsco O, Cohen C, Rosenthal R. Psoriasis Remission after Laparoscopic Roux-En-Y Gastric Bypass for Morbid Obesity. Obes Surg. 2004;14(8):1132-1134.

32. Kimball AB, Gladman D, Gelfand JM, et al. National Psoriasis Foundation clinical consensus on psoriasis comorbidities and recommendations for screening. J Am Acad Dermatol. 2008;58(6): 1031-1042.

33. Zou L, Lonne-Rahm SB, Helander A, Stokkeland K, Franck J, Nordlind K. Alcohol intake measured by phosphatidylethanol in blood and the lifetime drinking history interview are correlated with the extent of psoriasis. Dermatology. 2015;230(4):375-380.

34. Abedini R, Salehi M, Lajevardi V, Beygi S. Patients with psoriasis are at a higher risk of developing nonalcoholic fatty liver disease. Clin Exp Dermatol. 2015;40(7):722-727.

35. Crews FT, Bechara R, Brown LA, et al. Cytokines and alcohol. Alcohol Clin Exp Res. 2006;30(4):720-730.

36. Kawaguchi M, Mitsuhashi Y, Kondo S. Overexpression of tumour necrosis factor-alpha-converting enzyme in psoriasis. Br J Dermatol. 2005;152(5):915-919.

37. Ockenfels HM, Keim-Maas C, Funk R, Nussbaum G, Goos M. Ethanol enhances the IFN-gamma, TGF-alpha and IL-6 secretion in psoriatic co-cultures. Br J Dermatol. 1996;135(5):746-751.

38. Serwin AB, Sokolowska M, Dylejko E, Chodynicka B. Tumour necrosis factor (TNF-alpha) alpha converting enzyme and soluble TNF-alpha receptor type 1 in psoriasis patients in relation to the chronic alcohol consumption. J Eur Acad Dermatol Venereol. 2008;22(6): 712-717.

39. Dommasch ED, Li T, Okereke OI, Li Y, Qureshi AA, Cho E. Risk of Depression in Women with Psoriasis: A Cohort Study. Br J Dermatol. 2015;173(4):975-980.

40. Esposito M, Saraceno R, Giunta A, Maccarone M, Chimenti S. An Italian study on psoriasis and depression. Dermatology. 2006;212(2): 123-127.

41. Gupta MA, Gupta AK. Depression and suicidal ideation in dermatology patients with acne, alopecia areata, atopic dermatitis and psoriasis. Br J Dermatol. 1998;139(5):846-850.

42. Jensen P, Ahlehoff O, Egeberg A, Gislason G, Hansen PR, Skov L. Psoriasis and New-onset Depression: A Danish Nationwide Cohort Study. Acta Derm Venereol. Epub 2015 Jun 18.

43. Dowlatshahi EA, Wakkee M, Arends LR, Nijsten T. The prevalence and odds of depressive symptoms and clinical depression in psoriasis patients: a systematic review and meta-analysis. $J$ Invest Dermatol. 2014;134(6):1542-1551.

44. Tyring S, Gottlieb A, Papp K, et al. Etanercept and clinical outcomes, fatigue, and depression in psoriasis: double-blind placebo-controlled randomised phase III trial. Lancet. 2006;367(9504):29-35.

45. Fleming P, Roubille C, Richer V, et al. Effect of biologics on depressive symptoms in patients with psoriasis: a systematic review. J Eur Acad Dermatol Venereol. 2015;29(6):1063-1070.

46. Fordham B, Griffiths CE, Bundy C. A pilot study examining mindfulness-based cognitive therapy in psoriasis. Psychol Health Med. 2015;20(1):121-127.

47. Nelson PA, Keyworth C, Chisholm A, et al. 'In someone's clinic but not in mine' - clinicians' views of supporting lifestyle behaviour change in patients with psoriasis: a qualitative interview study. Br J Dermatol. 2014;171(5):1116-1122. 
Psoriasis: Targets and Therapy

\section{Publish your work in this journal}

Psoriasis: Targets and Therapy is international, peer-reviewed, open access journal focusing on psoriasis, nail psoriasis, psoriatic arthritis and related conditions, identification of therapeutic targets and the optimal use of integrated treatment interventions to achieve improved outcomes and quality of life. The manuscript management system

Submit your manuscript here: http://www.dovepress.com/psoriasis-targets-and-therapy-journal

\section{Dovepress}

is completely online and includes a very quick and fair peer-review system. Visit http://www.dovepress.com/testimonials.php to read real quotes from published authors. 